\title{
Mechanisms of bone metastases of breast cancer
}

\author{
Larry J Suva ${ }^{1,2,4}$, Robert J Griffin ${ }^{3,4}$ and Issam Makhoul ${ }^{4,5}$
}

\author{
${ }^{1}$ Departments of Orthopaedic Surgery, Barton Research Institute, Center for Orthopaedic Research, ${ }^{2}$ Physiology and Biophysics, \\ ${ }^{3}$ Radiation Oncology, ${ }^{4}$ Breast Cancer Research Program and ${ }^{5} \mathrm{Hematology}$ and Oncology, University of Arkansas for Medical \\ Sciences, Little Rock, Arkansas 72205, USA \\ (Correspondence should be addressed to L J Suva; Email: suvalarryj@uams.edu)
}

\begin{abstract}
Cancer development is a multi-step process driven by genetic alterations that elicit the progressive transformation of normal human cells into highly malignant derivatives. The altered cell proliferation phenotype of cancer involves a poorly characterized sequence of molecular events, which often result in the development of distant metastasis. In the case of breast cancer, the skeleton is among the most common of metastatic sites. In spite of its clinical importance, the underlying cellular and molecular mechanisms driving bone metastasis remain elusive. Despite advances in our understanding of the phenotype of cancer cells, the increased focus on the contribution of the tumor microenvironment and the recent revival of interest in the role of tumorpropagating cells (so called cancer stem cells) that may originate or be related to normal stem cells produced in the bone marrow, many important questions remain unanswered. As such, a more complete understanding of the influences of both the microenvironment and the tumor phenotype, which impact the entire multi-step metastatic cascade, is required. In this review, the importance of tumor heterogeneity, tumor-propagating cells, the microenvironment of breast cancer metastasis to bone as well as many current endocrine therapies for the prevention and treatment of metastatic breast cancer is discussed.
\end{abstract}

Endocrine-Related Cancer (2009) 16 703-713

\section{Introduction}

Cancer is a disorder of cell proliferation that involves a poorly characterized sequence of molecular events that include, uncontrolled cell proliferation, morphological and cellular transformation, angiogenesis, dysregulation of apoptosis, enhanced invasive activity, and subsequent local and distant metastases (Lin \& Karin 2007). It is abundantly clear that the tumor microenvironment, which develops and changes in parallel with tumor burden, is a central participant in this complex process (Coussens \& Werb 2002, de Visser et al. 2005).

Despite recent widespread patient screening advances as well as heightened health awareness, a significant proportion of women still present with advanced breast cancer. The diagnosis of a metastatic tumor suggests systemic treatment, along with local intervention targeting the primary tumor. Although there has been progress resulting from early detection and improved adjuvant therapy, the prognosis of breast cancer patients is still limited by the occurrence of distant metastases largely due to clinically occult micrometastases that remain undetected. In particular, breast cancer bone metastasis has unique characteristics; some of which have been successfully targeted in the palliative setting (Sweeney et al. 2007) but not yet with treatments of curative intent.

In developed countries, $\sim 75 \%$ of all breast cancers occur in postmenopausal women, of which about $80 \%$ are hormone receptor positive (Anderson et al. 2002). Metastasis accounts for over $90 \%$ of lethality in cancer patients (Bendre et al. 2003) and at post mortem examination, $\sim 70 \%$ of all patients dying of breast cancer have evidence of metastatic bone disease, which in many patients is a chronic condition (Coleman 2006). The survival from the time of diagnosis varies among different tumor types, whereas the prognosis after the development of bone metastases in breast 
cancer is considerably better than that after a recurrence at visceral sites (Coleman \& Rubens 1987). The median survival time from diagnosis of bone metastases from breast cancer is measurable in years (Coleman 2006), a number which may be linked to the increasing number of effective treatments available to slow the progression of the underlying disease and inhibiting tumor osteolysis.

In general, reducing the development of relapses is an important goal for adjuvant therapy. As the development of distant metastases has been consistently associated with eventual mortality from breast cancer, the measurement of distant metastatic spread may serve as a valuable surrogate marker for survival and has the potential to provide earlier results from clinical trials testing new types of adjuvant therapy (Rugo 2008).

In spite of its clinical importance, the underlying cellular and molecular mechanisms underlying the causes of bone metastasis remain elusive, despite vast information regarding the phenotype of cancer cells, the increased focus on the possible tumor-harboring bone tumor microenvironment, and the recent revival of interest in the role of tumor-propagating cells (so called cancer stem cells) that may originate or be related to normal stem cells produced in the bone marrow. As such, a more complete understanding of the influences of both the microenvironment and the tumor phenotype, which impact the entire multistep metastatic process, is required. In this review, the importance of tumor heterogeneity, tumor-propagating cells, the microenvironment of breast cancer metastasis to bone, and current endocrine therapies in the progression of metastatic breast cancer are discussed.

\section{The metastatic process and tumor heterogeneity}

Despite several decades of intensive investigation, controversy remains regarding the exact pathophysiologic mechanism(s) of metastasis. Two fundamentally different models for metastasis have been described (Weigelt et al. 2005). The first speculates that primary tumors in a specific organ arise from the same cell that later undergoes multiple changes leading to clonal evolution associated with phenotypic and behavioral diversity, including the potential to metastasize to distant organs (Talmadge 2007). The second suggests that cancers arising in a specific organ are initiated by the activation of the cancer stem cell compartment, thereby, driving the ability to metastasize with a variable predilection to different tissues (Talmadge 2007).

The prevailing concept of metastasis as a clonal evolution process is that during tumor progression under environmental pressure, heterogeneity in gene expression develops within the population of tumor cells, for example due to the effects of genomic instability and the accumulation of mutations and other genetic aberrations. Clonal selection then determines that only those tumor cells that have acquired the necessary properties to initiate the complex process of metastasis are able to disseminate successfully and go on to form secondary tumors (Fidler 2003). The growth of a tumor focus at a site distant to the primary tumor represents the final step in the complex process of metastasis, which is the result of numerous sequential and selective events. Implicit in the clonal selection (evolution) hypothesis is the development of at least one tumor subpopulation within the primary tumor that expresses the genes required to successfully complete the process of metastasis (Talmadge 2007). Hence, primary tumors must also include cellular subpopulations that express none or only a subset of the characteristics required to complete the entire metastatic process (Talmadge 2007).

Tumor progression per se suggests that metastatic cells are exclusively found within metastases, but not necessarily within primary tumors. Rather, tumor progression should be considered as a continuum that does not end with metastasis; but continues during therapeutic intervention such that variants develop, which may have increased resistance to therapy as well as preferential features compatible with metastatic growth. Thus, tumor cells within a metastasis have completed a process of colonization at the metastatic site, the result of initially expressing all of the alterations necessary for metastasis and growth at that site, e.g. bone. However, as metastatic foci grow, heterogeneity can again develop potentially including cells with different metastatic capabilities and potential (Talmadge 2007). Such a process has been described in numerous studies, including studies evaluating bone marrow micrometastases at the time of initial breast cancer diagnosis. In this case, heterogeneous tumor cells in the bone marrow was a significant prognostic factor with respect to both poor overall survival and breast-cancer-specific survival, suggesting that both primary and metastatic cells contribute to tumor progression. Indeed, micrometastatic cells may have the potential to re-seed the primary tumor site, adding to the well-accepted idea that a significant component of tumor progression is associated with the seeding of tumor cells into the circulation from both the primary 
and the metastatic (Norton \& Massague 2006) sites. Thus, although all metastases are derived from the parent tumor, the actual seeding of new metastases likely occurs at various times depending on the stage of clonal selection (evolution) in the primary tumor. To be certain, individual cancer cells that differ in their metastatic capability co-exist within a tumor, such that metastatic primary tumors contain tumor subpopulations with widely variant metastatic potential (Talmadge 2007).

Histological examination and gene expression profiling of primary tumors support this idea and shows cellular heterogeneity based on both morphology and gene expression (Kang et al. 2003, Gupta \& Massague 2006, Wood et al. 2007). For example, morphologically diverse areas can occur within a tumor such as foci of ductal carcinoma in situ within a primary breast carcinoma (Leonard \& Swain 2004) or the different bone metastases of a single patient with metastatic prostate cancer (Roudier et al. 2003). Similarly, estrogen receptor (ER), Her2/neu, or p53 expression varies between and within tumors and metastases, ranging from 1 to $>90 \%$ of cells (Talmadge 2007). This variability is also seen with regard to tumor physiological status. Tumor oxygenation as well as glycolysis and resulting tumor acidity has been found to widely vary between primary and metastatic lesions - even in the same patient (Raghunand et al. 2003, Van den Eynden et al. 2007,
Gatenby et al. 2007). Thus, the clonal selection of metastases leads to phenotypically diverse metastases, such that within the same patient some metastases can be positive whereas others are negative for specific marker(s) and the individual metastases more or less responsive to systemic therapy.

Metastasis to any site, including the skeleton, is a non-random process (Gupta \& Massague 2006). While certain tumors preferentially metastasize to specific sites, others are less selective and more widespread. The selectivity for a specific target site is determined by the ability of the tumor cells to accomplish all of the steps of the complex metastatic cascade (Poste \& Fidler 1980, Fidler 2003). Although anatomical and mechanical effects such as blood flow influence the sites of tumor metastasis, to some degree, it is eventually the microenvironment that not only promotes tumor proliferation at the distant site, but also determines which metastatic site(s) is preferred. This process is accomplished by the complex manipulation of the host microenvironment by a series of events including secretion of systemic factors from the primary tumor site (Kelly et al. 2005), adhesion of the tumor cells to endothelial cells at the metastatic site, extravasation into the target tissue, and subsequent colonization and growth of the lesion (Bendre et al. 2003; Fig. 1).

Breast cancer's proclivity for bone is frequently associated with intractable bone pain, pathological

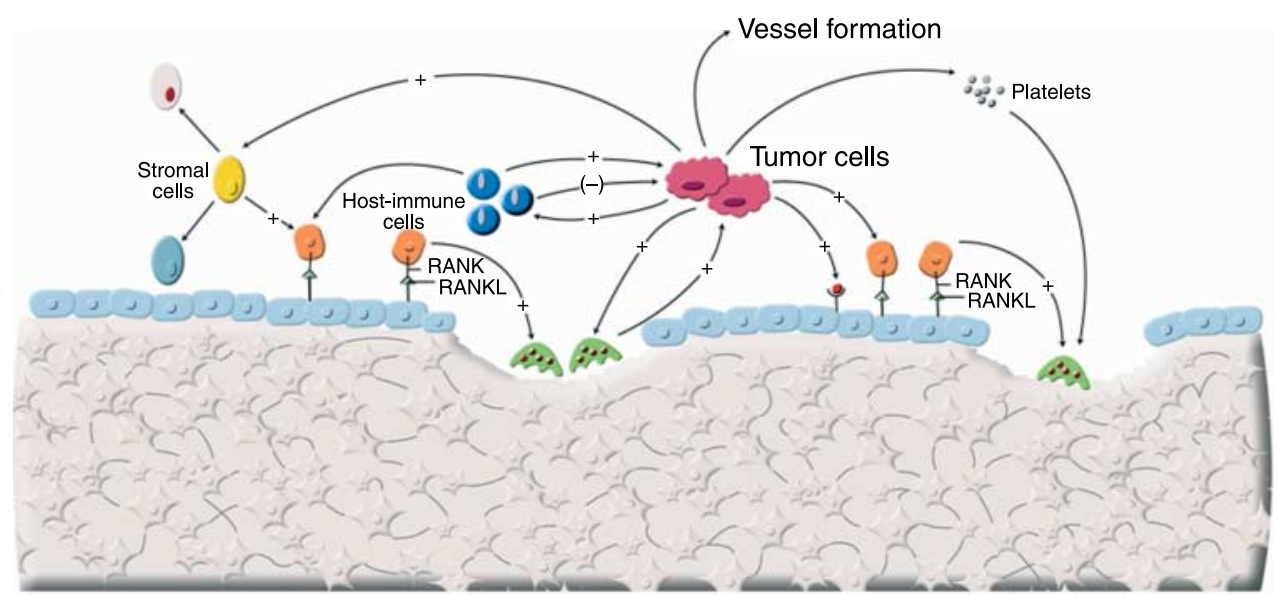

Figure 1 Schematic of tumor-bone marrow microenvironment interactions. Invading tumor cells secrete osteolytic factors that can directly and indirectly stimulate osteoclastic bone resorption, by multinucleated osteoclasts (shown as green cells). Indirect stimulation is primarily by up-regulation of RANK-RANKL signaling by osteoblasts (shown as cuboidal pale blue cells on bone surface) or by stimulation of host immune cells that can increase RANK-RANKL signaling and also negatively regulate tumor cells. Tumor cells also secrete factors that can activate other receptors on the osteoblast, leading to increased osteolysis. Tumors also secrete agents such as VEGF and PDGF that influence vessel formation, as well as agents that can alter platelet function, both of which support osteoclastogenesis and osteolysis. Tumor cells may also influence other bone marrow microenvironment cells, such as stromal cells, which can be induced to differentiate towards the adipogeneic lineage (white cell; red nuclei) or that can become osteoblasts or that can otherwise support osteoclast progression through interactions in the bone marrow niche. The overall integrated result of increased tumor burden in bone in the case of metastatic breast cancer is increased osteolysis. 
fractures, nerve compression, and hypercalcemia due to osteolysis (Mundy 2002) and is a feature distinct from locoregional and visceral spread. The pattern of disease progression, response to therapy, and ultimately patient survival following diagnosis is subject to extremely wide variation (Sweeney et al. 2007). One potential explanation for these differences may be the ease with which tumor cells that have escaped into the circulation proliferate in selected secondary tissues. Alternatively, it is possible that the skeleton may harbor breast cancer cells of lower level metastatic potential than other extra-mammary sites, or perhaps that tumor cells once confined to the skeleton may not have the aggressiveness of breast cancers metastatic to other organs, such as liver or lung. For whatever reasons, the diagnosis of breast cancer bone metastases is insufficient for subsequent patient management decisions. Rather, attention is paid clinically to the presence of concurrent visceral metastases, skeletal tumor load, and the expression of relevant tumor therapeutic targets. However, the possibility that tumor cells harbored in the bone or bone marrow from early on in the patient history could be detected or measured and have a larger role in patient management decisions remains relatively underexplored. One thing is certain; skeletal tumors such as the bone metastases of breast cancer and the associated extensive bone destruction often denote a dramatic worsening in the prognosis for the patient with significantly increased morbidity (Bhattacharyya et al. 2007).

\section{Tumor-initiating cells and metastasis}

Interest has recently re-emerged in the stem cell theory of cancer, stating that tumors contain rare cells with infinite growth and variable potential and propensity to metastasize to different tissues ( $\mathrm{Li}$ et al. 2007). These cells may metastasize and some of the cells within the metastatic foci may then differentiate into cells without a metastatic phenotype. However, it is not clear whether tumor stem cells are bone fide stem cells or simply represent a highly malignant cellular subpopulation (Talmadge 2007). Recent studies have suggested that these tumor-propagating cells may not in fact be that rare. Using transplanted mouse leukemias and lymphomas in syngeneic animals, rather than xenotransplantation, the majority of tumors were maintained by the dominant cell population, and not by a minor tumor growth-sustaining subpopulation (Kelly et al. 2007). Regardless of whether tumor-initiating cells are 'stem' cells that underwent transformation or other progenitor cells that gained access to particular 'stem cell programs and functions' and are hence immortalized, it is clear that these cancer cells possess many stem cell properties.

ER expressing mammary cells represent the minority of normal breast tissue. Maintenance of breast tissue requires the controlled proliferation and differentiation of mammary stem cells that do not express the ER- $\alpha$. Some stem cells acquire the expression of ER- $\alpha$ as they differentiate but the mechanism of ER- $\alpha$ acquisition remained unknown until recently. Estrogen action on the mammary gland is mediated through its action on ER-expressing stromal cells or the minority of mammary cells that express the ER- $\alpha$; this effect is then amplified through local paracrine mechanisms using different growth factors (Morani et al. 2008). The role of BRCA $1 / 2$ mutations in breast cancer was established several years ago (Miki et al. 1994, Wooster et al. 1995). BRCA1-mutated breast cancers are characterized by the absence of ER, progesterone receptor, and HER2 expression, medullary histologic type, early age of onset, and aggressive clinical behavior with visceral predilection. BRCA1 is a multifunctional tumor suppressor gene that plays a major role in the regulation of stem/progenitor fate (Liu et al. 2008). Furthermore, wild-type BRCA1 and Oct1 are necessary for the expression of ER- $\alpha$ while mutated BRCA1 leads to a lack of expression of ER- $\alpha$ (Hosey et al. 2007). Since BRCA1 can be silenced in patients with sporadic forms of breast cancer by hypermethylation (Wei et al. 2005) or specific mutations (John et al. 2007), it is possible that the dysregulation of BRCA1 or other components of this pathway in breast stem cells is responsible for many of the so-called triple-negative breast cancers and their characteristic aggressive behavior typically involving more visceral than bone metastases. Alternatively, if breast cancer arises in differentiating progenitor cells that have acquired ER- $\alpha$ expression, different programs would likely be accessible to these cells that have the potential to increase the proclivity of these cells to metastasize to bone.

Recent studies utilizing immortalized human mammary epithelial cell populations have suggested that specific cellular programs can be activated that contribute substantially to tumor formation and progression (Mani et al. 2008). As an example, the epithelial-mesenchymal transition (EMT) is an important developmental process that changes the phenotypic and functional properties of cells. EMT likely contributes to metastasis by changing the adhesive properties of particular tumor cells and promoting motility, thereby also increasing tumor cell invasiveness (Onder et al. 2008). Collectively, 
the evidence strongly supports the idea that the individual characteristics of tumors span the spectrum between clonal selection or cancer stem cells. Consequently, if tumor growth is sustained either by rare cancer stem cells or dominant clones or some combination of both, any successful therapeutic approach will likely require targeting multiple tumor cell populations (Talmadge 2007, Adams \& Strasser 2008).

\section{The role of the microenvironment in bone metastasis}

The striking contrast between the abundance of circulating tumor cells and the relative rarity of metastatic events strongly suggests that the metastatic process is very inefficient and takes much more than simply the presence of cancer cells in the circulation (Gupta \& Massague 2006). Once a cell has overcome the intrinsic barriers to carcinogenesis, it will need to overcome additional environmental barriers that have been evolutionarily perfected to protect multicellular organisms and maintain their homeostasis (Poste \& Fidler 1980, Fidler 2003). Typical environmental barriers include physical (basement membrane), chemical (reactive oxygen species (ROS), hypoxia, and low PH), and biological (immune surveillance, inhibitory cytokines, and regulatory extracellular matrix (ECM) peptides) components (Kelly et al. 2005, Van den Eynden et al. 2007).

Once distant from the primary tumor site and resident in the bone narrow, breast cancer cells establish a tight interaction with the marrow microenvironment (Onder et al. 2008). Resident metastatic breast cancer cells secrete a plethora of osteolytic factors (Bendre et al. 2003), capable of both receptor activator of NF- $\kappa \mathrm{B}$ ligand (RANKL)-dependent and -independent activation of osteoclast formation and bone resorption (Lu et al. 2007; Fig. 1). Tumor activation of bone resorption occurs via direct activation of osteoclasts, and their precursors derived from the monocyte/macrophage lineage cells resident in the bone marrow, and are independent of RANKL (Bendre et al. 2003). Monocytes are also activated to form osteoclasts via indirect effects on osteoblasts, leading to osteoclastogenesis mediated by RANKL. In the presence of colony-stimulating factor 1 (CSF1), RANK-L promotes the entire process of osteoclastogenesis and the activation of bone resorption (Fig. 1).

Interestingly, once dysregulated, the critical pathways involved in mammary gland development are also implicated in mammary tumor formation and progression. In addition, epidermal growth factor, fibroblast growth factor (FGF), transforming growth factor- $\beta$ and the $W n t$ gene family are all implicated in the development and progression of metastatic breast cancer (Mundy 2002, Bussard et al. 2008).

In addition to the metastatic breast cancer cells that have reached the bone marrow, other cell types within the bone microenvironment contribute to the development of tumor cell micrometastatic foci within the bone marrow or the so-called bone metastatic niche. These other cell types can be considered to be one of two general types, either resident stromal or transient cells (Bussard et al. 2008). Stromal cells include mesenchymal stem cells that give rise to adipocytes, fibroblasts, chrondrocytes, or osteoblasts. In addition, these resident stromal cells in the bone marrow have the ability to support the differentiation, proliferation, and survival of both hematopoetic and cancer cells. Stromal cell expression of vascular cell adhesion molecule (VCAM-1) has been shown to increase the production of osteolytic cytokines in multiple myeloma. For example, treatment with a neutralizing antibody to VCAM-1 significantly inhibited myeloma bone disease (Michigami et al. 2000).

Resident vascular endothelial cells also contribute to a bone marrow microenvironment particularly favorable to metastatic cancer cells. The high microvessel density of the bone marrow has been shown to be associated with both an increased bone-tumor metastasis frequency as well as the prolonged survival of tumor cells (Chavez-Macgregor et al. 2005). Clearly, new blood vessels are essential for the survival of metastatic cancer cells. In addition, many secreted tumor-cell factors (e.g. interleukin 8 (IL-8)) are known to increase endothelial cell proliferation, differentiation, and even angiogenesis, suggesting the existence of a feedback loop that improves tumor cell survival at the distant location (Bussard et al. 2008).

Transient cells that contribute to the metastatic bone microenvironment include erythrocytes, $\mathrm{T}$ cells, and platelets, all of which are derived from hematopoietic stem cells. Of these, the platelet is particularly interesting. One recent study has demonstrated that platelet adhesion to MDA-MB-231 breast cancer cells resulted in the secretion of lysophosphatidic acid (LPA (1-acyl-sn-glycero-3-phosphate)) from platelets (Boucharaba et al. 2004). In addition, the release of LPA resulted in the increased expression of IL-8 from tumor cells, a molecule with potent osteoclastogenic activity (Bendre et al. 2005). These data provide a mechanism by which platelet adhesion to tumor cells can mediate local changes in tumor osteolysis. Similarly, a critical role for platelets in mediating metastasis has been suggested in studies by Jain et al. (2007). T cells that express RANKL as well as secrete 
TNF- $\alpha$ are well-recognized mediators of bone resorption that can be activated by metastatic tumor cells. Tumor-derived parathyroid hormone-related protein (PTHrP) and IL-8 activate transient $\mathrm{T}$ cells, thus enhancing bone resorption (Marguiles et al. 2006).

PTHrP and CSF1 (both associated with human breast cancer bone metastasis) are involved in the preparation of the breast for lactation and have been shown to play an important role in the communication between the breast, bone, and bone marrow (Wysolmerski et al. 2002). PTHrP, a protein originally identified as the agent responsible for the humoral hypercalcemia of malignancy (Suva et al. 1987), is released from maturing alveolar and ductal cells at the end of pregnancy and during lactation to induce calcium mobilization from the skeleton for milk production (Thiede \& Rodan 1988, Wysolmerski et al. 1995).

CSF1 is a glycosylated proteoglycan that acts on its unique cell surface receptor, the CSF-1R encoded by $c$-fms protooncogene expressed on the surface of osteoclast precursors (Hofstetter et al. 1992), and is essential for osteoclast progenitor survival. CSF-1 is also expressed (without its receptor) at low levels in resting non-lactating breast tissue both in the epithelial compartment and in the stroma (Kacinski 1997). Interestingly, CSF-1 levels have recently been shown to correlate with breast cancer risk in postmenopausal but not premenopausal women (Tamimi et al. 2008).

\section{Predictors of tumor recurrence and bone metastasis}

Breast cancer is a heterogeneous disease that presents in a number of clinical and histological forms. Clinically, progression is difficult to predict using the available prognostic factors and treatment is therefore not as effective as it needs to be in order to improve patient outcomes. Importantly, therapeutic strategies would likely be more successful if more was understood about breast cancer heterogeneity and metastasis.

Traditional histopathologic factors describing breast cancer have been evaluated for their association with organ tropism for more than a century (Paget 1889). The respective role of classical tumor characteristics and patient demographics on the incidence of bone metastasis as first site of recurrence in patients with breast cancer have also been extensively examined (James et al. 2003). Low tumor grade, ER positivity, and lymph node involvement are significantly associated with bone metastasis. Tubular mixed primary tumors were also associated with more bone metastases compared with ductal tumors, whereas neither age nor tumor size were significantly associated with bone metastases (James et al. 2003). In this study, factors significantly associated with increased survival time in patients presenting with bone metastases were ER status, the absence of additional sites of metastatic disease, normal tumor markers, and long metastasisfree interval. Although the association of ER-positive breast cancer with bone metastases has been reported in many studies (Koenders et al. 1991, Coleman et al. 1998, Solomayer et al. 2000), another study in patients with invasive ductal carcinoma of the breast (Hasebe et al. 1998) suggested that regardless of the lymph node or ER status, the presence of fibrotic focus (FF) and its grade (diameter $>8 \mathrm{~mm}$, FF fibrosis grade 1 ) in the primary tumor were the most important predictive factors for bone metastasis.

The demonstration that tumor-derived PTHrP was responsible for the humoral hypercalcemia of malignancy (Suva et al. 1987) suggested a potential role in predisposing the skeletal complications of breast cancer. In the only large prospective study of consecutive unselected patients with operable breast cancer, PTHrP expression by the primary tumor predicted improved prognosis with decreased metastasis to all sites (Henderson et al. 2006). This surprising result implicated an effect, as yet unknown, and clearly distinct from the well-characterized osteolytic action of tumor-derived PTHrP expression locally in bone marrow.

In order to identify potential molecular mechanisms involved in determining the site of relapse, Smid et al. (2006) mapped differentially expressed genes from 107 primary breast tumors patients who were lymph node negative at the time of diagnosis and had experienced relapse. A panel of 69 genes was identified as significantly differentially expressed between patients who experienced relapse to bone versus those who experienced relapse elsewhere in the body. Five of the functionally annotated genes were members of the FGF receptor pathway (FGF5, SOS1, DUSP1, FGFR3, and $D U S P 4)$. Numerous studies have reported similar gene expression-based approaches (van de Vijver et al. 2002, Kang et al. 2003, Sorlie et al. 2003, Van't Veer \& Weigelt 2003, Wang et al. 2005, Bild et al. 2006, Bueno-de-Mesquita et al. 2008); however, many of the identified classifiers and gene targets in the various studies are largely non-overlapping, raising questions about their biologic significance and clinical implications (Massague 2007). The obvious implication from these collective observations is that other approaches such as proteomics or 'non-omic'-based assays are required to validate and/or define those 
pathways and targets identified by gene expression profiling as predictive of tumor development and progression (Bhattacharyya et al. 2007).

\section{Current treatment of bone metastasis}

\section{Local therapeutic strategies}

Since much of the therapeutic strategy for bone metastasis is palliative in nature, the tumor bed is often irradiated before or after primary tumor site surgery (Riccio et al. 2007). Agents such as bisphosphonates have steadily increased in use to inhibit bone resorption in combination with more traditional therapy targeting cancer cells as discussed below (Kohno 2008). The results of each of these approaches alone or in combination are influenced by the extent of other systemic disease present at the time of treatment.

Many bone metastases will be irradiated using external beam radiotherapy simply because this approach will improve clinical symptoms of pain and other morbidity by $70 \%$ or more in many studies (Hoegler 1997). Other approaches involving thermal ablation have recently gained limited popularity, with some promising studies demonstrating that many solitary lesions in bone can be effectively destroyed with a variety of currently available thermal therapy devices (Simon \& Dupuy 2006, Masala et al. 2007).

Important new information regarding other related sequellae from the growth of breast cancer in bone has been gained using antiresorptive agents such as bisphosphonates or RANKL-targeted agents that inhibit bone resorption. Therefore, there is some optimism that radiation therapy in combination with targeted agents may improve treatment options and significantly lengthen survival in some instances. This optimism is of course based on the hope that clinical studies using well-designed combination therapy approaches will be designed and implemented.

\section{Systemic therapy}

The proclivity of breast cancer to metastasize to bone and the prognostic significance of bone metastasis suggest that effective bone metastasis treatment may provide significant clinical benefit. As described above, specific bone metastasis-associated targets may improve therapeutic efficacy. However, many factors have been identified that have been linked with the progression of breast cancer in bone. The determination of which (if any) of these factors play crucial roles in the pathogenesis and progression of breast cancer bone metastasis awaits continued investigation.
The aggressive lytic phenotype of breast cancer bone metastasis has resulted in therapies that primarily target osteoclastic bone resorption, such as the bisphosphonates (Coleman 2006). It is now well-accepted that bisphosphonate use has a beneficial effect on the management of metastatic bone disease and the prevention of treatment-induced bone loss (Coleman 2008). Guidelines for the use of bisphosphonates in preventing treatment-induced bone loss are continuing to evolve and clinical trials investigating their potential role in the adjuvant setting to prevent metastasis are ongoing (Coleman 2008).

The final results of one of these trials (ABCSG-12) have recently been presented (Gnant et al. 2008). The study evaluated the role of the bisphosphonate zoledronic acid in a group of premenopausal women who received an LHRH analog and either tamoxifen or anastrozole and who were then randomized to receive zoledronic acid or placebo. No difference in diseasefree survival was seen with any endocrine therapy tested, but the bisphosphonate zoledronic acid conferred a $36 \%$ decrease in recurrences (disease free survival (DFS), hazard ratio (HR): 0.64 (0.46-0.91) $P=0.011)$ in the bone, extraskeletal sites including the ipsilateral and controlateral breast as well as visceral sites. The explanation of these results remains elusive, but a direct systemic effect of zoledronic acid on the tumor seems unlikely as the primary site of zoledronic acid uptake is the skeleton.

Although ongoing clinical trials targeting breast cancer bone metastasis may provide effective treatments, a better understanding of how breast cancer cells selectively metastasize to bone is required to provide effective treatments for this challenging clinical problem. All available evidence strongly supports the notion that osteoclasts are an appropriate target and that the inhibition of the activity and/or development of these cells provides clinical benefit for the treatment of breast cancer bone metastasis. In this vein, other developing and highly promising therapies for breast cancer bone metastasis include cathepsin $\mathrm{K}$ inhibitors, anti-DKK antibodies, and denosumab, a fully human monoclonal antibody that can reversibly bind human RANKL and potently inhibit osteoclastogenesis and bone resorption (Dougall \& Chaisson 2006, Lipton et al. 2007).

Recently, adjuvant aromatase inhibitor therapy has also become well-established as a breast cancer therapy for postmenopausal women with hormone receptorpositive breast cancer (Ellis et al. 2008). Several recent clinical trials comparing aromatase inhibitors with tamoxifen have confirmed that aromatase inhibitors offer significant advantages over tamoxifen during 
the treatment phase (Coates et al. 2007, Coombes et al. 2007, Forbes et al. 2008). However, such systemic therapy with these inhibitors is also complicated by a highly accelerated bone loss and subsequent increased fracture risk (Forbes et al. 2008). There are a variety of agents available to reduce the effects of metastatic breast cancer on the skeleton and also local treatments that may target individual bone tumors. Whether or not these agents can be used in concert to improve bone quality, reduce morbidity from the metastatic lesions, and increase quality of life and survival remains to be studied.

\section{Summary}

Normal interactions between the mammary gland and the bone/bone marrow-derived cells are diverted to serve the mammary malignant process at its inception and subsequently during the metastatic process. It is now formally a possibility that the bone marrow has the potential to serve as a 'sanctuary' to protect metastatic breast cancer cells. This protective environment may support the metastatic foci before they progress locally to form bony metastases or equally serve as a platform from which breast cancer cells can be stimulated locally or systemically to seed other organs or even re-seed the site of the original primary tumor (Fig. 1). If true, the idea that the bone is categorically a site reserved for only palliative therapy in response to disease progression is one that needs to be revised in the minds of researchers and clinicians alike.

The currently available data suggest that different tumor-propagating cells (so-called tumor stem cells) are the origin of each subtype of breast cancer, with hormone receptor-negative breast cancer arising from an earlier developmental stage compared with hormone receptor-positive breast cancer. This may explain the difference in activated pathways in each subtype and therefore in propensity to metastasize to bone. However, since bone metastases arise in both types of breast cancer, it is likely that different pathways can also be used by breast cancer cells to establish residence in the bone/bone marrow microenvironment. The identification and resolution of these pathways remains one of the most important issues in breast cancer research, with critical implications in the prevention and treatment of disease.

Targeting osteoclastic bone resorption with bisphosphonates has proven to be a useful strategy with improvement of quality of life in the metastatic setting and of disease-free survival in the adjuvant setting (RANKL inhibitors are still under investigation); yet more therapeutic targets are needed. Even in the face of the many advances and data described above, many crucial questions remained unanswered. How do tumor cells remain dormant for years in spite of their presence in the bone marrow microenvironment? How do we identify the specific signature of a metastatic cell? How can the bone cancer cell niche be targeted, protected, and prevented?

As expected, ongoing research efforts are attempting to answer these and many other important and fundamental questions. With certainty, it is reasonable to state that significantly more research is required before the skeletal consequences of metastasis will be completely understood. It is our conviction that the relationship of the primary tumor microenvironment and the bone marrow microenvironment, where circulating tumor cells may find sanctuary and later develop into bone lesions, dictates tumor cell survival and activation, response to first-line therapy, and recurrence patterns in each patient. Therefore, the characteristics of each microenvironment are a proper place to focus efforts on improved interventions to care for our patients.

\section{Declaration of interest}

The authors' state that there is no conflict of interest that could be perceived as prejudicing the impartiality of the article.

\section{Funding}

This work was supported by the Carl L Nelson Chair of Orthopaedic Creativity.

\section{Author contribution statement}

All authors contributed equally to the design, writing, and preparation of the article.

\section{References}

Adams JM \& Strasser A 2008 Is tumor growth sustained by rare cancer stem cells or dominant clones? Cancer Research 68 4018-4021.

Anderson WF, Chatterjee N, Ershler WB \& Brawley OW 2002 Estrogen receptor breast cancer phenotypes in the surveillance, epidemiology, and end results database. Breast Cancer Research and Treatment 76 27-36.

Bendre M, Gaddy D, Nicholas RW \& Suva LJ 2003 Breast cancer metastasis to bone: it is not all about PTHrP. Clinical Orthopaedics and Related Research $\mathbf{4 1 5}$ Supplement S39-S45.

Bendre MS, Margulies AG, Walser B, Akel NS, Bhattacharrya S, Skinner RA, Swain F, Ramani V, Mohammad KS, Wessner LL et al. 2005 Tumor-derived 
interleukin-8 stimulates osteolysis independent of the receptor activator of nuclear factor-kappaB ligand pathway. Cancer Research 65 11001-11009.

Bhattacharyya S, Byrum S, Siegel ER \& Suva LJ 2007 Proteomic analysis of bone cancer: a review of current and future developments. Expert Review of Proteomics 4 371-378.

Bild AH, Yao G, Chang JT, Wang Q, Potti A, Chasse D, Joshi MB, Harpole D, Lancaster JM, Berchuck A et al. 2006 Oncogenic pathway signatures in human cancers as a guide to targeted therapies. Nature 439 353-357.

Boucharaba A, Serre CM, Gres S, Saulnier-Blache JS, Bordet JC, Guglielmi J, Clezardin P \& Peyruchaud O 2004 Platelet-derived lysophosphatidic acid supports the progression of osteolytic bone metastases in breast cancer. Journal of Clinical Investigation 114 1714-1725.

Bueno-de-Mesquita JM, Linn SC, Keijzer R, Wesseling J, Nuyten DS, van Krimpen C, Meijers C, de Graaf PW, Bos MM, Hart AA et al. 2008 Validation of 70-gene prognosis signature in node-negative breast cancer. Breast Cancer Research and Treatment [in press].

Bussard KM, Gay CV \& Mastro AM 2008 The bone microenvironment in metastasis; what is special about bone? Cancer Metastasis Review 27 41-55.

Chavez-Macgregor M, Aviles-Salas A, Green D, Fuentes-Alburo A, Gomez-Ruiz C \& Aguayo A 2005 Angiogenesis in the bone marrow of patients with breast cancer. Clinical Cancer Research 11 5396-5400.

Coates AS, Keshaviah A, Thurlimann B, Mouridsen H, Mauriac L, Forbes JF, Paridaens R, Castiglione-Gertsch M, Gelber RD, Colleoni M et al. 2007 Five years of letrozole compared with tamoxifen as initial adjuvant therapy for postmenopausal women with endocrine-responsive early breast cancer: update of study BIG 1-98. Journal of Clinical Oncology 25 486-492.

Coleman RE 2006 Clinical features of metastatic bone disease and risk of skeletal morbidity. Clinical Cancer Research 12 6243s-6249s.

Coleman RE 2008 Risks and benefits of bisphosphonates. British Journal of Cancer 98 1736-1740.

Coleman RE \& Rubens RD 1987 The clinical course of bone metastases from breast cancer. British Journal of Cancer 55 61-66.

Coleman RE, Smith P \& Rubens RD 1998 Clinical course and prognostic factors following bone recurrence from breast cancer. British Journal of Cancer 77 336-340.

Coombes RC, Kilburn LS, Snowdon CF, Paridaens R, Coleman RE, Jones SE, Jassem J, Van de Velde CJ, Delozier T, Alvarez I et al. 2007 Survival and safety of exemestane versus tamoxifen after 2-3 years' tamoxifen treatment (Intergroup Exemestane Study): a randomised controlled trial. Lancet 369 559-570.

Coussens LM \& Werb Z 2002 Inflammation and cancer. Nature 420 860-867.

Dougall W \& Chaisson M 2006 Monoclonal antibody targeting RANKL as a therapy for cancer-induced bone diseases. Clinical Calcium 16 627-635.
Ellis GK, Bone HG, Chlebowski R, Paul D, Spadafora S, Smith J, Fan M \& Jun SR 2008 Randomized trial of denosumab in patients receiving adjuvant aromatase inhibitors for nonmetastatic breast cancer. Journal of Clinical Oncology 26 4875-4882.

Van den Eynden GG, Van Laere SJ, Van der Auwera I, Gilles L, Burn JL, Colpaert C, van Dam P, Van Marck EA, Dirix LY \& Vermeulen PB 2007 Differential expression of hypoxia and (lymph)angiogenesis-related genes at different metastatic sites in breast cancer. Clinical and Experimental Medicine 24 13-23.

Fidler IJ 2003 The pathogenesis of cancer metastasis: the 'seed and soil' hypothesis revisited. Nature Reviews Cancer 3 453-458.

Forbes JF, Cuzick J, Buzdar A, Howell A, Tobias JS \& Baum M 2008 Effect of anastrozole and tamoxifen as adjuvant treatment for early-stage breast cancer: 100-month analysis of the ATAC trial. Lancet Oncology 9 45-53.

Gatenby RA, Smallbone K, Maini PK, Rose F, Averill J, Nagle RB, Worrall L \& Gillies RJ 2007 Cellular adaptations to hypoxia and acidosis during somatic evolution of breast cancer. British Journal of Cancer 97 646-653.

Gnant M, Mlineritsch B, Luschin-Ebengreuth G, Kainberger F, Kassmann H, Piswanger-Solkner JC, Seifert M, Ploner F, Menzel C, Dubsky P et al. 2008 Adjuvant endocrine therapy plus zoledronic acid in premenopausal women with early-stage breast cancer: 5-year follow-up of the ABCSG-12 bone-mineral density substudy. Lancet Oncology 9 840-849.

Gupta GP \& Massague J 2006 Cancer metastasis: building a framework. Cell 127 679-695.

Hasebe T, Tsuda H, Hirohashi S, Shimosato Y, Tsubono Y, Yamamoto H \& Mukai K 1998 Fibrotic focus in infiltrating ductal carcinoma of the breast: a significant histopathological prognostic parameter for predicting the long-term survival of the patients. Breast Cancer Research and Treatment 49 195-208.

Henderson MA, Danks JA, Slavin JL, Byrnes GB, Choong PF, Spillane JB, Hopper JL \& Martin TJ 2006 Parathyroid hormone-related protein localization in breast cancers predict improved prognosis. Cancer Research 66 2250-2256.

Hoegler D 1997 Radiotherapy for palliation of symptoms in incurable cancer. Current Problems in Cancer 21 129-183.

Hofstetter W, Wetterwald A, Cecchini MC, Felix R, Fleisch H \& Mueller C 1992 Detection of transcripts for the receptor for macrophage colony-stimulating factor, c-fms, in murine osteoclasts. PNAS 89 9637-9641.

Hosey AM, Gorski JJ, Murray MM, Quinn JE, Chung WY, Stewart GE, James CR, Farragher SM, Mulligan JM, Scott AN et al. 2007 Molecular basis for estrogen receptor alpha deficiency in BRCA1-linked breast cancer. Journal of the National Cancer Institute 99 1683-1694. 
Jain S, Zuka M, Liu J, Russell S, Dent J, Guerrero JA, Forsyth J, Maruszak B, Gartner TK, Felding-Habermann B et al. 2007 Platelet glycoprotein Ib alpha supports experimental lung metastasis. PNAS 104 9024-9028.

James JJ, Evans AJ, Pinder SE, Gutteridge E, Cheung KL, Chan S \& Robertson JF 2003 Bone metastases from breast carcinoma: histopathological - radiological correlations and prognostic features. British Journal of Cancer 89 660-665.

John EM, Miron A, Gong G, Phipps AI, Felberg A, Li FP, West DW \& Whittemore AS 2007 Prevalence of pathogenic BRCA1 mutation carriers in 5 US racial/ ethnic groups. Journal of the American Medical Association 298 2869-2876.

Kacinski BM 1997 CSF-1 and its receptor in breast carcinomas and neoplasms of the female reproductive tract. Molecular Reproduction and Development $\mathbf{4 6}$ 71-74.

Kang Y, Siegel PM, Shu W, Drobnjak M, Kakonen SM, Cordon-Cardo C, Guise TA \& Massague J 2003 A multigenic program mediating breast cancer metastasis to bone. Cancer Cell 3 537-549.

Kelly T, Suva LJ, Huang Y, Macleod V, Miao HQ, Walker RC \& Sanderson RD 2005 Expression of heparanase by primary breast tumors promotes bone resorption in the absence of detectable bone metastases. Cancer Research 65 5778-5784.

Kelly PN, Dakic A, Adams JM, Nutt SL \& Strasser A 2007 Tumor growth need not be driven by rare cancer stem cells. Science 317337.

Koenders PG, Beex LV, Langens R, Kloppenborg PW, Smals AG \& Benraad TJ 1991 Steroid hormone receptor activity of primary human breast cancer and pattern of first metastasis. The Breast Cancer Study Group. Breast Cancer Research and Treatment 18 27-32.

Kohno N 2008 Treatment of breast cancer with bone metastasis: bisphosphonate treatment - current and future. International Journal of Clinical Oncology 13 18-23.

Leonard GD \& Swain SM 2004 Ductal carcinoma in situ, complexities and challenges. Journal of the National Cancer Institute 96 906-920.

Li F, Tiede B, Massague J \& Kang Y 2007 Beyond tumorigenesis: cancer stem cells in metastasis. Cell Research 17 3-14.

Lin WW \& Karin M 2007 A cytokine-mediated link between innate immunity, inflammation, and cancer. Journal of Clinical Investigation 117 1175-1183.

Lipton A, Steger GG, Figueroa J, Alvarado C, Solal-Celigny P, Body JJ, de Boer R, Berardi R, Gascon P, Tonkin KS et al. 2007 Randomized active-controlled phase II study of denosumab efficacy and safety in patients with breast cancer-related bone metastases. Journal of Clinical Oncology 25 4431-4437.

Liu S, Ginestier C, Charafe-Jauffret E, Foco H, Kleer CG, Merajver SD, Dontu G \& Wicha MS 2008 BRAC1 regulates human mammary stem/progenitor cell fate. PNAS 105 1680-1685.
Lu Y, Cai Z, Xiao G, Keller ET, Mizokami A, Yao Z, Roodman GD \& Zhang J 2007 Monocyte chemotactic protein-1 mediates prostate cancer-induced bone resorption. Cancer Research 67 3646-3653.

Mani SA, Guo W, Liao MJ, Eaton EN, Ayyanan A, Zhou AY, Brooks M, Reinhard F, Zhang CC, Shipitsin M et al. 2008 The epithelial-mesenchymal transition generates cells with properties of stem cells. Cell 133 704-715.

Marguiles AG, Klimberg VS, Bhattacharrya S, Gaddy D \& Suva LJ 2006 Genomics and proteomics of bone cancer. Clinical Cancer Research 12 6217s-6221s.

Masala S, Manenti G, Roselli M, Mammucari M, Bartolucci DA, Formica V, Massari F \& Simonetti G 2007 Percutaneous combined therapy for painful sternal metastases: a radiofrequency thermal ablation (RFTA) and cementoplasty protocol. Anticancer Research 27 4259-4262.

Massague J 2007 Sorting out breast-cancer gene signatures. New England Journal of Medicine 356 294-297.

Michigami T, Shimizu N, Williams PJ, Niewolna M, Dallas SL, Mundy GR \& Yoneda T 2000 Cell-cell contact between marrow stromal cells and myeloma cells via VCAM-1 and alpha(4)beta(1)-integrin enhances production of osteoclast-stimulating activity. Blood 96 1953-1960.

Miki Y, Swensen J, Shattuck-Eidens D, Futreal PA, Harshman K, Tavtigian S, Liu Q, Cochran C, Bennett LM, Ding W et al. 1994 A strong candidate for the breast and ovarian cancer susceptibility gene BRCA1. Science 266 66-71.

Morani A, Warner M \& Gustafsson JA 2008 Biological functions and clinical implications of oestrogen receptors alfa and beta in epithelial tissues. Journal of Internal Medicine 264 128-142.

Mundy GR 2002 Metastasis to bone: causes, consequences and therapeutic opportunities. Nature Reviews. Cancer 2 584-593.

Norton L \& Massague J 2006 Is cancer a disease of self-seeding? Nature Medicine 12 875-878.

Onder TT, Gupta PB, Mani SA, Yang J, Lander ES \& Weinberg RA 2008 Loss of E-cadherin promotes metastasis via multiple downstream transcriptional pathways. Cancer Research 68 3645-3654.

Paget S 1889 The distribution of secondary growths in cancer of the breast. Lancet i 571-573.

Poste G \& Fidler IJ 1980 The pathogenesis of cancer metastasis. Nature 283 139-146.

Raghunand N, Gatenby RA \& Gillies RJ 2003 Microenvironmental and cellular consequences of altered blood flow in tumours. British Journal of Radiology 76 S11-S22.

Riccio AI, Wodajo FM \& Malawer M 2007 Metastatic carcinoma of the long bones. American Family Physician 76 1489-1494.

Roudier MP, True LD, Higano CS, Vesselle H, Ellis W, Lange P \& Vessella RL 2003 Phenotypic heterogeneity of end-stage prostate carcinoma metastatic to bone. Human Pathology 34 646-653. 
Rugo HS 2008 The importance of distant metastases in hormone-sensitive breast cancer. Breast 17 S3-S8.

Simon CJ \& Dupuy DE 2006 Percutaneous minimally invasive therapies in the treatment of bone tumors: thermal ablation. Seminars in Musculoskeletal Radiology 10 137-144.

Smid M, Wang Y, Klijn JG, Sieuwerts AM, Zhang Y, Atkins D, Martens JW \& Foekens JA 2006 Genes associated with breast cancer metastatic to bone. Journal of Clinical Oncology 24 2261-2267.

Solomayer EF, Diel IJ, Meyberg GC, Gollan C \& Bastert G 2000 Metastatic breast cancer: clinical course, prognosis and therapy related to the first site of metastasis. Breast Cancer Research and Treatment 59 271-278.

Sorlie T, Tibshirani R, Parker J, Hastie T, Marron JS, Nobel A, Deng S, Johnsen H, Pesich R, Geisler S et al. 2003 Repeated observation of breast tumor subtypes in independent gene expression data sets. PNAS 100 8418-8423.

Suva LJ, Winslow GA, Wettenhall RE, Hammonds RG, Moseley JM, Diefenbach-Jagger H, Rodda CP, Kemp BE, Rodriguez H, Chen EY et al. 1987 A parathyroid hormone-related protein implicated in malignant hypercalcemia: cloning and expression. Science 237 893-896.

Sweeney KJ, Boland PJ \& King T 2007 The management of asymptomatic skeletal breast cancer: a paradigm shift. Annals of Surgical Oncology 14 2430-2431.

Talmadge JE 2007 Clonal selection of metastasis within the life history of a tumor. Cancer Research 67 11471-11475.

Tamimi RM, Brugge JS, Freedman ML, Miron A, Iglehart JD, Colditz GA \& Hankinson SE 2008 Circulating colony stimulating factor- 1 and breast cancer risk. Cancer Research 68 18-21.

Thiede MA \& Rodan GA 1988 Expression of a calciummobilizing parathyroid hormone-like peptide in lactating mammary tissue. Science 242 278-280.

Van't Veer LJ \& Weigelt B 2003 Road map to metastasis. Nature Medicine 9 999-1000.

van de Vijver MJ, He YD, van't Veer LJ, Dai H, Hart AA, Voskuil DW, Schreiber GJ, Peterse JL, Roberts C,
Marton MJ et al. 2002 A gene-expression signature as a predictor of survival in breast cancer. New England Journal of Medicine 347 1999-2009.

de Visser KE, Korets LV \& Coussens LM 2005

De novo carcinogenesis promoted by chronic inflammation is B lymphocyte dependent. Cancer Cell 7 411-423.

Wang Y, Klijn JG, Zhang Y, Sieuwerts AM, Look MP, Yang F, Talantov D, Timmermans M, Meijer-van Gelder $\mathrm{ME}, \mathrm{Yu} \mathrm{J}$ et al. 2005 Gene-expression profiles to predict distant metastasis of lymph-node-negative primary breast cancer. Lancet 365 671-679.

Wei M, Grushko TA, Dignam J, Hagos F, Nanda R, Sveen L, Xu J, Fackenthal J, Tretiakova M, Das S et al. 2005 BRCA1 promoter methylation in sporadic breast cancer is associated with reduced BRCA1 copy number and chromosome 17 aneusomy. Cancer Research $\mathbf{6 5}$ 10692-10699.

Weigelt B, Peterse JL \& van 't Veer LJ 2005 Breast cancer metastasis: markers and models. Nature Reviews. Cancer 5 591-602.

Wood LD, Parsons DW, Jones S, Lin J, Sjoblom T, Leary RJ, Shen D, Boca SM, Barber T, Ptak J et al. 2007 The genomic landscapes of human breast and colorectal cancers. Science 318 1108-1113.

Wooster R, Bignell G, Lancaster J, Swift S, Seal S, Mangion J, Collins N, Gregory S \& Gumbs C 1995 Identification of the breast cancer susceptibility gene BRCA2. Nature 378 789-792.

Wysolmerski JJ, McCaughern-Carucci JF, Daifotis AG, Broadus AE \& Philbrick WM 1995 Overexpression of parathyroid hormone-related protein or parathyroid hormone in transgenic mice impairs branching morphogenesis during mammary gland development. Development 121 3539-3547.

Wysolmerski JJ, Dann PR, Zelazny E, Dunbar ME, Insogna KL, Guise TA \& Perkins AS 2002 Overexpression of parathyroid hormone-related protein causes hypercalcemia but not bone metastases in a murine model of mammary tumorigenesis. Journal of Bone and Mineral Research 17 1164-1170. 